\title{
Validity of a Model Based on Transaction Costs in Identifying the Benefits of IOS: The Electronic Data Interchange Case
}

\author{
Piercarlo Maggiolini ${ }^{1}$, Ramon Salvador Valles ${ }^{2, *}$ \\ ${ }^{1}$ Politecnico di Milano, Milan, I20123, Italy \\ ${ }^{2}$ Technical University of Catalonia - Barcelona Tech, Barcelona, E08028, Spain
}

\begin{abstract}
Company competitiveness often depends on key relationships with other companies and information technologies play a critical role in supporting these relationships. Nevertheless, tools to analyse the impact of technology on businesses are in short supply. This article presents the results of research performed in companies in the mass consumer industry aimed at verifying the validity of a proposed model based on transaction costs, to be used for impact evaluation of inter-organizational systems in companies. The model, which takes into account different kinds of benefits, is applied in an exploratory way to the identification of benefits from using electronic data interchange systems as an e-commerce tool to support business to business relationships. Verification of the proposed model confirms its usefulness for the identification of benefits, mainly for those occurring at the inter-organizative level.
\end{abstract}

Keywords Evaluation, Transaction Costs, Electronic Data Interchange, Inter-organizational Systems

\section{Introduction}

This research lies within the scope of the evaluation of results obtained with the introduction of an inter-organizational system (IOS) in the business process of companies. We propose a model that considers different types of benefits in terms of the transaction cost theory and, in an exploratory way, verifies the validity and limitations of this model in identifying the benefits obtained from using electronic data interchange (EDI) systems in companies in the consumer goods sector.

Empirical verification of the usefulness of the proposed model in a standard technology in use for several years enables us to observe the wide ranging impact of this technology on organizations and so ensure the validity of the test results and the proposed model. The use of EDI is considered in a value added networks setting.

The model used to evaluate the impact of the information and communication technologies (ICTs) on companies draws on the conceptual proposal of the theory of transaction $\operatorname{costs}([1,2])$ and so especially considers the impact on exchanges taking place within and outside companies.

To verify the validity and limitations of the proposed model and its results, the following were considered:

- Analysis of whether the cost and benefit components

* Corresponding author:

rsalvadorvalles@yahoo.com (Ramon Salvador Valles)

Published online at http://journal.sapub.org/ac

Copyright (C) 2012 Scientific \& Academic Publishing. All Rights Reserved identified in the theoretical method proposed for evaluating the results of EDI introduction are perceived in the same way by the companies that use the technology.

- Analysis of the applicability of this model to the evaluation of the benefits obtained from the introduction and use of EDI and related technologies (bar code labellers, optical readers, etc) by a group of companies in the consumer goods sector.

- Analysis of the influence of process costs and benefits for different technology architectures, not only for EDI but also for the monitoring of strategies such as efficient consumer response (ECR) and efficient consumer management $(E C M)$.We also examined whether the empirical work of various authors confirms the transactional approach proposed here and to identify similar components in reducing costs or increasing benefits. This is done for the case of EDI, but also for new Internet technologies applied to e-commerce to support business to business (B2B) relationships.

This article describes the model proposed for assessing the benefits (Section 2), analyses the potential impact of EDI on process cost and benefit components (Section 3) and, on an exploratory basis, analyses the model's applicability to ten companies. The article concludes with a discussion of results (Section 4) and identification of the main conclusions (Section 5).

\section{The Transactional Approach to Evaluating Benefits}


The benefits of using ICTs have often been classified generically as operational and strategic. Operational benefits are understood to be benefits that mainly contribute to the improvement of process efficiency, whereas strategic benefits are those that improve the competitive position of a company.

The ICTs have a clear impact on processes located internally in a company (especially those in the inter-organiza tional space) and on relationships with partners. Technology's impact on activities and interrelationships can be formalized as a value chain[3]. The impact of ICTs is evident regarding the components (activities and relationships) of the value chains of companies involved in the business process (suppliers and customers), i.e., within the value system[4].

Using the ICTs to improve customer service to, in turn, improve strategy and competitiveness, is likely to result in access to new customers or the achievement of a minimum cost. This is a key issue for firms in sectors like the consumer goods sector, where product and service differentiation and cost reduction represent important opportunities and threats.

Competitiveness can be particularly enhanced through the innovative use of technology $([5,6])$ and especially the implementation of ECR and ECM strategies. The outcome is a strategic impact on the organization and the market.

The expected impact of EDI on activities and interrelationships corresponding to the value chain and value system, among other reasons, have justified the claim of authors to address, from the perspective of transaction costs, the evaluation of the results of implementing this technology in enterprises. A preliminary screening of companies that have used EDI seems to confirm the capacity of the proposed model for identifying and subsequently evaluating EDI benefits using the theoretical transaction costs framework.

In the proposed model, the operational benefits of ICT introduction can be classified in three levels: lower production costs, reduced organizational costs for internal coordination and reduced costs for external transactions. These, coupled with the impact of environment variables, lead to strategic benefits and competitive advantages. While this aspect is not directly part of this proposed model, it is understood to take place, and models such as Porter's analysis will be needed in addition to the approach taken here.

\subsection{Lower Production Costs}

A priori, the use of ICTs can potentially impact the following:

- Automation: crafts, activities or procedures performed by hand replaced with those performed by machines.

- Media transfers: the ability to transfer a file via email eliminates operations such as copying, reading, writing, etc.

- Parasitic functions: unexpected situations that accompany an activity without contributing to its result (e.g., a busy phone).

- Availability and speed: downtime and waiting times reduced when an optical reader is used.

\subsection{Reduced Internal Coordination Costs}

The impact of the ICTs on the costs of organizing the economic activity of a company generally includes the following:

- Faster and more frequent planning cycles, thanks to improved responsiveness to changing environmental conditions.

- Identification and control of critical sectors.

- Achievement of forecasts maintained.

- Encouragement and enhancement of lateral relations, including direct contact, the task force and the team.

- Reduction of the need for mediation.

\subsection{Reduced External Transaction Costs}

The transaction cost components that could be affected by the use of the ICTs include:

- Lower costs related to locating the best options.

- Reduced contractual procedure costs related to negotiation and conclusion.

- Lower control and regulation costs related to maintenance of the transaction.

A significant portion of the reduction in these costs is due to the ICTs impact on opportunistic behaviour by participants and the reduction in information asymmetry.

\section{Benefits of EDI under the Transactional Approach}

In the particular case of the introduction of EDI, the benefits to be gained at the operational and strategic levels have been identified by several authors([7-13]). Other studies analyse the benefits of the implementation of emerging technologies in e-commerce([14-19]).

The benefits to firms of adopting EDI are classified according to the framework proposed by the transaction costs model, which offers a way for companies to anticipate the impact of the introduction of the technology and observe possible reductions in costs and benefits.

The benefits to be achieved by the implementation of EDI depend on the specific situation of each company, but they include the benefits from EDI and related technologies involved in the processes, whether EAN bar code labels, scanners, optical readers, etc.

There are two basic conditions for companies to derive the maximum benefit from EDI. The first is integration between the EDI network and the internal computer system, measured by the number and different kinds of documents used. The second is to use EDI with as many partners as possible([7-20]). In addition, the degree of innovation in business processes introduced by EDI and strategies such as ECR, cooperative work, etc. will also affect the level of benefits.

Given the conditions for the introduction of EDI that apparently ensure satisfactory results, the main components of the benefit (or cost reduction) affected by the technology are now identified from a transactional point of view.

\subsection{Classification of Benefits}


The benefits from introducing EDI technology in business processes can be classified following the proposed evaluation model in three groups: production benefits, internal organization benefits and external organization benefits.

\subsubsection{Innovation Benefits for Production}

In this case the benefits of EDI are very evident, with time savings due to easily quantifiable productivity benefits obtained from the four factors listed below:

- Staff savings due to automation: there is no need to copy or type data repeatedly, open/close envelopes, etc.

- Reduction in transfers between different media: information can now travel through the same network without the need to move from computer to fax to telephone, etc.

- Reduction in parasitic functions: information is transferred automatically to the user without the need for non-productive activities.

- Reduced downtime and shorter waiting times lead to faster business processes.

\subsubsection{Innovation Benefits for Internal Organization}

Since EDI is primarily a communication medium with the outside world, the benefits for internal transactions arise from the benefits for external transactions and computer integration. Thus, EDI achieves external integration that boosts the creation of internal networks or intranets and improves internal organizational processes. EDI influences internal data flows in three ways:

- By modifying their characteristics and the processing activities necessary to place orders, such as frequency, the amount of data to be sent and data transmission time and by modifying the flows related to shipping instructions, invoices, messages between activities and the electronic catalogue of products or services.

- By creating new flows and processing activities, such as payment communication, delivery summaries, invoice summaries and the business account situation, as support to managing supplies and deliveries.

- By eliminating flows and processing activities, such as those related to errors and disputes, as well as the flows that disappear with the creation of new processes.

\subsubsection{Innovation Benefits for External Organization}

The transaction under the proposed model is divided into three phases: search, contractual procedures and action (maintaining the transaction).

- Search: the main EDI applications are not of great significance at this stage, but one possible application is advertising, whose potential impact is important in the workplace and in the catalogue providing information about the company and its products.

- Contractual procedures: likewise, EDI impact here is minimal. While relationships between partners through EDI standards and regulations are more formal, contract drafting and monitoring is facilitated.

- Operation and maintenance: EDI can change information flows in three ways:

- Providing: information flows regarding orders and shipping instructions are faster and more reliable and so can be performed more frequently while the number of invoices is reduced.

- Creating: customers can receive summaries of deliveries and invoices, vendors can receive payment communications and customers can be informed about delivery times and so prepare for reception.

- Removing: flows caused by errors or missing information are removed.

\subsection{Comparison of Traditional and Transactional Approaches}

Table 1. Main components of the traditional and transactional approaches, The EDI case

\begin{tabular}{l} 
Traditional approach (major components) \\
\hline - Staff costs \\
Reduced data input costs \\
Reduced mail and file preparation costs \\
Reduced personal attention costs \\
- Paper and communication costs \\
Reduced stationery and mail costs \\
Reduced information storage costs \\
- Infrastructure costs \\
Reduced logistical and warehousing costs \\
- Financial costs \\
Reduced working capital needs \\
- Information costs \\
Reduced transport and information production costs \\
Reduced stock breakage \\
\hline Transactional model (major components) \\
\hline PRODUCTION COSTS: \\
- Time costs (production costs) \\
Time savings for faster message flows. \\
Enhanced information exchange. \\
SEARCH COSTS: \\
- Business information costs \\
Through both the job and catalogue, EDI ensures complete and updated \\
information. \\
TRANSACTION MAINTENANCE COSTS: \\
- Coordination with logistics operators \\
Benefits are enhanced by integrating EDI with logistics operators. \\
- Added services \\
Services that are only possible with EDI, such as summaries of deliv- \\
eries, invoices and sales accounts. \\
- Regulation or control and dispute costs \\
EDI documents are inherently accepted by both partners, and disputes \\
are eliminated. \\
EDI eliminates and removes all the consequences. \\
\hline
\end{tabular}

While the basic benefit of computerized production processes is economies of scale, the main benefit of the implementation of ICTs for internal and external management processes is the company response to the market at the most appropriate time, mode and cost. According to several authors these benefits may be termed benefits of scope and fitness.

The traditional approach to analysing benefits for the company, established primarily on vertical relationships, is especially directed towards benefits analysis from the financial point of view and highlights the benefits associated 
with time savings and economies of scale. The transactional view, which considers the company as mainly dealing with internal and external exchanges, highlights organizational benefits and thus the ability to achieve economies of scope and fitness.

Table 1 shows the main benefit components that identify each evaluation approach: the traditional one based on financial considerations, and the transactional approach proposed in this article.

\section{Results}

The exploratory study was carried out in ten companies in the consumer goods sectors, all EDI users supported by the AECOM value added network operating in Spain. EDI-AECOM is the subset of messages used by the Spanish Commercial Coding Association (AECOC) according to the United Nations/EDI standard for Administration, Commerce and Transport (UN/EDIFACT). The companies included seven manufacturers of food products (pasta and meal, snacks, beverages, wines and spirits) employing between 300 and 1,700 workers, two chemicals manufacturers (detergents and paints) employing 250 and 750 workers and a retail company employing 2,500 workers.

A semi-structured questionnaire was used to collect information from heads of information systems department that was then tabulated and analysed.

The results obtained confirm the validity of the proposed transactional model in its ability to identify cost and benefit components deriving from the use of EDI. The profits of these companies due to the use of this technology in business processes overlapped with the components identified in the proposed model. Hence, once the components have been identified, they can be used to measure the level of benefit.

\subsection{Validity of the Transactional Model}

In assessing the impact of EDI on companies that facilitates the transactional model, the new contributions especially touch on external transaction processes but also identify the impact on processes within companies. The results of the analysis of the interviews allow us to confirm which cost components are affected by the introduction of technology.

The impact of technology on these process components can be perceived a priori, because of the nature of EDI and the business processes it supports. However, the proposed model enables this to be seen in a much clearer way. It can be observed that companies effectively identify the cost components proposed by the model.

This model thus initially identifies the different cost components related to the process activities and benefits in relation to transactions, and facilitates the measurement of both quantitative and pseudo-quantitative benefits.

Table 2. Process costs and benefit components under the transactional approach to evaluating EDI

\begin{tabular}{|c|c|c|c|c|c|c|c|c|c|c|c|c|}
\hline \multicolumn{3}{|r|}{ BENEFITS } & 1 & 2 & 3 & 4 & 5 & 6 & 7 & 8 & 9 & 0 \\
\hline \multirow{2}{*}{ 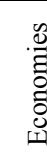 } & \multirow{2}{*}{$\overbrace{\breve{\Xi}}^{\Xi}$} & Reduction in time required to receive and process files and documents & $\bullet$ & $\bullet$ & $\bullet$ & & $\bullet$ & $\bullet$ & & $\bullet$ & $\bullet$ & $\bullet$ \\
\hline & & Paper savings & $\bullet$ & $\bullet$ & $\bullet$ & & $\bullet$ & $\bullet$ & $\bullet$ & $\bullet$ & $\bullet$ & $\bullet$ \\
\hline \multirow{4}{*}{\multicolumn{2}{|c|}{ نْ }} & Reduced stocks & $\bullet$ & $\bullet$ & $\bullet$ & & & & & & & \\
\hline & & Fewer stock-outs and delays & & $\bullet$ & $\bullet$ & & $\bullet$ & & $\bullet$ & $\bullet$ & $\bullet$ & $\bullet$ \\
\hline & & More accurate and current information on partners and products & $\bullet$ & $\bullet$ & $\bullet$ & & $\bullet$ & & & $\bullet$ & & $\bullet$ \\
\hline & & Elimination of error and dispute resolution activities & $\bullet$ & $\bullet$ & $\bullet$ & & $\bullet$ & $\bullet$ & $\bullet$ & $\bullet$ & $\bullet$ & $\bullet$ \\
\hline \multirow{13}{*}{ 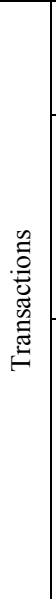 } & \multirow{3}{*}{ 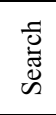 } & Distribution and collection of accurate information on products and partners & $\bullet$ & $\bullet$ & $\bullet$ & & $\bullet$ & & $\bullet$ & $\bullet$ & $\bullet$ & $\bullet$ \\
\hline & & More time for searches & & & & & $\bullet$ & & $\bullet$ & $\bullet$ & & \\
\hline & & More focused and faster advertising & & & & & $\bullet$ & & $\bullet$ & $\bullet$ & & \\
\hline & \multirow{4}{*}{ 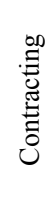 } & Possibility of contracting deals instantly & & & & & & & & & & \\
\hline & & Ability to instantly respond to offers & & & & & & & & & & \\
\hline & & Special offers launched more easily & & & & & & & & & & \\
\hline & & More time to expend on contracts & & & & & $\bullet$ & & $\bullet$ & $\bullet$ & & \\
\hline & \multirow{6}{*}{ 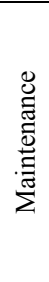 } & More flexible procurement & $\bullet$ & $\bullet$ & $\bullet$ & & $\bullet$ & & $\bullet$ & $\bullet$ & & \\
\hline & & Elimination of problems caused by errors & $\bullet$ & $\bullet$ & $\bullet$ & & $\bullet$ & $\bullet$ & $\bullet$ & $\bullet$ & & \\
\hline & & Elimination of disputes & & $\bullet$ & $\bullet$ & & $\bullet$ & $\bullet$ & $\bullet$ & $\bullet$ & & \\
\hline & & $\begin{array}{c}\text { Reduced time spent on transactions because of new messages (communication } \\
\text { of payment, summaries of deliveries, etc) }\end{array}$ & $\bullet$ & $\bullet$ & $\bullet$ & & $\bullet$ & $\bullet$ & $\bullet$ & $\bullet$ & & \\
\hline & & More efficient and flexible supply through integration with logistics operators & & & $\bullet$ & & $\bullet$ & & $\bullet$ & $\bullet$ & & \\
\hline & & More time available for transaction maintenance & & & & & & & & & & \\
\hline \multirow{5}{*}{\multicolumn{2}{|c|}{$\stackrel{\dot{\Xi}}{\dot{E}}$}} & Current customers retained & 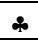 & \& & & \& & & \& & $\$$ & \& & * & 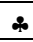 \\
\hline & & Increased number of potential customers & $\leftrightarrow$ & $\leftrightarrow$ & & $\leftrightarrow$ & & & & & & \\
\hline & & Improved customer service & & & & 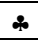 & \& & & 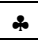 & 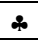 & \& & 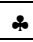 \\
\hline & & Better supply chain use & & & $\leftrightarrow$ & & \& & & & & & \\
\hline & & Alliances with other companies & & & & & & & & & & \\
\hline
\end{tabular}

- Detected only for the transactional model. ^ Detected only for the traditional analysis. $\bullet$ Detected for both models 
Table 2 shows the proposed transactional model components identified by companies with integrated EDI. Only two companies (numbers 4 and 6) failed to identify the various components and this was because communication networks were not integrated in their internal business processes. Note also that while the traditional approach focuses on the evaluation of components related to economies of time, these components are also considered by the transactional model. This shows the power of the proposed model itself, which includes other variables as well as economies of time.

However, the transactional model was unable to assess strategic benefits, grouped under the heading 'Other', unlike the traditional or ex-post assessment model. It should be noted that efforts were made to incorporate an assessment of such benefits in the financial methods, along with benefits that we could classify as difficult to quantify or intangible, such as better customer service, loyalty, etc. Some such proposals have been made by several authors[21].

Table 2 also shows the little regard for components related to contractual procedure benefits by the companies in the study. This would probably indicate that the current capacity of EDI to act in this area is underestimated by the companies.

\subsection{Remarks}

It is to be noted that a high percentage of companies use EDI and related technologies, such as e-commerce tools, thereby improving business-to-business (B2B) relationships and integration, in order to automate electronic document processing along the supply chain. This is confirmed by several authors who claim that classic EDI remains a technology that is widely used and forms the basis for many IOS. Nevertheless, the emergence of Internet-based communications is also having a positive effect on EDI use[22].

It has also been noted that the proposed model, empirically verified at the time, still has full validity according to contributions made by various authors, who have confirmed the impact of EDI on the components identified initially. While these investigations take different approaches, many of them deal with transaction costs related to searching, contracting and monitoring-control within value added EDI networks.

For example, the following benefits are identified in the supplier-manufacturer relationship that relies on EDI: (1) shorter order cycles, greater availability, lower purchase prices and lower transaction costs[11]; (2) successful coordination of firm operations with those of external business partners and streamlining of management-related processes[12]; and (3) cost reductions, mainly costs such as freight, inventory and information handling, reduced transaction costs of information processing and improved coordination[13].

We can see that IOS use (and research) has been expanding to include related areas, such as supply chain management and electronic commerce initiatives, involving more extensive integration of business processes and using a variety of emerging technologies, such as the Extensible Markup Language (XML)-based standard RosettaNet and
ebXML and Radio Frequency Identification[23]. The benefits that companies derive from using these new technologies are still under analysis in many scenarios; nevertheless, it is expected that the use of web-based EDI will be consistent with higher levels of coordination among the supply chain partners and overall performance, compared with the use of traditional EDI.

For example, when comparing the benefits of classic EDI with the new data format based on XML, for the case of the RosettaNet framework (electronics industry), it is verified, from a transaction cost perspective, that there are differences in favour of the latter in the benefit components discussed, and these are significant for business relationships, customer/supplier responsiveness, potential partners, new business models and better control of supply/demand processes[18]. Generally speaking, it would appear that new information technology used in IOS can reduce the transaction costs associated with external sourcing, especially search and monitoring costs, thereby favouring greater use of markets[14]; as a result, greater use of these systems is associated with more outsourcing of manufacturing[16]. In the absence of new empirical research, this could also help to confirm the validity of the transaction costs and of our proposed model as a useful perspective for empirical research to identify the benefits of IOS.

\section{Conclusions}

This research verified the validity of the proposed model based on transaction cost theory in identifying the benefits of the implementation of EDI as a precursor to evaluation. It has been observed that economies of time are among the components identified by both the proposed transactional model and the traditional model. The transactional model also highlighted benefits other than those offered by the traditional model, especially in external organizational processes (transactions). In these processes the identified benefits are associated with greater flexibility, the elimination of errors and disputes and the creation of new flows that facilitate planning and coordination outside the company.

It is to be noted that the benefits of EDI are substantial when the company integrates the technology with the company's internal computer system and with a large number of external partners. It also seems to be the case that the impact of EDI on the different components of the model depends significantly on the architecture of the ICTs used to effectively support the components of the value system. However, analysis of this precise point is still in progress.

In summary, while the traditional approach especially identifies the benefits of economies of scale, the transactional approach emphasizes economies of scope and adaptation to demand. This makes the evaluation of the impact of inter-organizational systems easier in terms of determining the convenience of replacing the vertical integration of companies with more complex market structures with the aim of improving their competitiveness. 


\section{ACKNOWLEDGEMENTS}

A seminal article was published showing the proposal and its validation[24].

\section{REFERENCES}

[1] R. H. Coase, The Nature of the Firm, in O. E. Williamson and S. E. Masten, 1999, The Economics of Transaction Costs, Edward Elgar Publishing Ltd., USA, 1937.

[2] O. E. Williamson, Transaction-cost economics: the governance of contractual relations, in Economic Organization: Firms, Markets and Policy Control, Wheatsheaf books, UK, 1986.

[3] M. E. Porter, Competitive Advantage: Creating and sustaining superior advantage, Free Press, USA, 1985.

[4] M. E. Porter, V. E. Millar, How information gives you competitive advantage, Harvard Business Review, vol. 63, no. 4, pp. 149-160, 1985.

[5] F. W. McFarlan, Information Technology changes the way you compete, Harvard Business Review, vol. 62, no. 3, pp. 98-103, 1984.

[6] N. Venkatraman, IT-Enabled Business Transformation: From Automation to Business Scope Redefinition, Sloan Management Review, vol. 35, no. 2, pp. 73-87, 1994.

[7] F. Bergeron, L. Raymond, Managing EDI for corporate advantage: A longitudinal study, Information \& Management, vol. 31, no. 6, pp. 319-333, 1997.

[8] S. Baile, The EDI success evaluation in the SME: An integrated model, Annals of Telecommunications, vol. 58, no. 2, pp. 297-328, 2003.

[9] S. Lee, H. Ahn, Structural equation model for EDI controls: Controls design perspective, Expert Systems with Applications, vol. 36, pp. 1731-1749, 2009.

[10] M. M. Rahim, G. Shanks, R. B. Johnston, A cross industry comparison of inter-organizational systems implementation activities, Electron Commer Res, vol. 11, pp. 215-243, 2011.

[11] L. N. K. Leonard, C. C. Davis, Supply chain replenishment: before-and-after EDI implementation, Supply Chain Management: An International Journal, vol. 11, no. 3, pp. 225-232, 2006.

[12] J. Y. Son, S. Narasimhan, F. J. Riggins, N. Kim, Understanding the Development of IOS-Based Trading Partner Relationships: A Structural Model with Empirical Validation, Journal of Organizational Computing and Electronic Com- merce, vol. 18, pp. 34-60, 2008.

[13] K. Ch. Tan, V. R. Kannan, Ch. Ch. Hsu, G. K. Leong, Supply chain information and relational alignments: mediators of EDI on firm performance, International Journal of Physical Distribution \& Logistics Management, vol. 40, no. 5, pp. 377-394, 2010.

[14] I. Bardhan, S. Mithas, S. Lin, Performance Impacts of Strategy, Information Technology Applications, and Business Process Outsourcing in U.S. Manufacturing Plants, Production and Operations Management, vol. 16, no. 6, pp. 747-762, 2007.

[15] T. Oliveira, M. Martins, Understanding e-business adoption across industries in European countries, Industrial Management \& Data Systems, vol. 110, no. 9, pp. 1337-1354, 2010.

[16] J. Dedrick, K. L. Kraemer, Impacts of internal and interorganizational information systems on the outsourcing of manufacturing, Journal of Strategic Information Systems, vol. 19, pp. 78-95, 2010.

[17] E. Hartono, X. Li, K. S. Na, J. T. Simpson, The role of the quality of shared information in interorganizational systems use, vol. 30, pp. 399-407, 2010.

[18] J. M. Nurmilaakso, J. Kauremaa, Business-to-business integration: Applicability, benefits and barriers in the telecommunications industry, Computers in Industry, vol. 63, pp. 45-52, 2012.

[19] L. Raymond, F. Bergeron, Enabling the business strategy of SMEs through e-business capabilities. A strategic alignment perspective, Industrial Management \& Data Systems, vol.108, no. 5, pp .577-595, 2008.

[20] P. Schubert, C. Legner, B2B integration in global supply chains: An identification of technical integration scenarios, vol. 20, pp. 250-267, 2011.

[21] P. Maggiolini, Office Technology Benefits: a Framework, Information \& Management, vol.10, no. 2, pp. 75-81, 1986.

[22] S. Narayanan, A. S. Marucheck, R. B. Handfield, Electronic Data Interchange: Research Review and Future Directions, Decision Sciences, vol. 40, no. 1, pp. 121-163, 2009.

[23] D. Robey, I. Ghiyoung, J.D. Wareham, Theoretical Foundations of Empirical Research on Interorganizational Systems: Assessing Past Contributions and Guiding Future Directions, Journal of the Association for Information Systems, vol. 9, no. 9, pp. 497-518, 2008.

[24] P. Maggiolini, R. S. Valles, Validity of a model based on the transaction costs to identify the benefits from IOS, Gestão e Produção, vol. 9, no. 3, pp-235-244, 2002. 